\title{
A design framework for additive manufacturing
}

\author{
H. Bikas ${ }^{1} \cdot$ A. K. Lianos ${ }^{1} \cdot$ P. Stavropoulos ${ }^{1}$ \\ Received: 26 January 2019 / Accepted: 20 March 2019 / Published online: 9 May 2019 \\ (C) The Author(s) 2019
}

\begin{abstract}
Additive manufacturing (AM) is one of the fastest growing and most promising manufacturing technologies, offering significant advantages over conventional manufacturing processes. That is, the geometrical flexibility that leads to increased design freedom is not infinite as the numerous AM processes impose manufacturing limitations. Abiding by these manufacturability rules implies a backpropagation of AM knowledge to all design phases for a successful build. A catholic AM-driven design framework is needed to ensure full exploitation of the AM design capabilities. The current framework is based on the definition of the CAD aspects and the AM process parameters. Their dependence, affection to the resulted part, and weight on the total process determine the outcome. The AM-driven design framework prevents manufacturing issues of certain geometries, that can be effortlessly created by conventional manufacturing, and additionally exploits the full design-freedom potentials AM has to offer with a linear design flow reducing design iterations and ultimately achieving first time right AM design process.
\end{abstract}

Keywords Additive manufacturing $\cdot$ Design for AM $\cdot$ AM design framework $\cdot$ Manufacturability $\cdot$ Design aspects $\cdot$ Design considerations

\section{Introduction}

One of the most promising value propositions of the additive manufacturing technologies is the zero-cost geometry flexibility, assuming part manufacturability. Benefits such as design freedom, integrated design, production flexibility with no need of product-specific tools, and lead time reduction for short series production are assets that AM can offer to the industrial sector [1,2]. Yet the wide spectrum of AM technologies comes along with numerous manufacturing limitations [3].

These limitations emerge to the latest phases of a part design, which causes multiple design iterations until complete obedience to the AM rules for manufacturability. P. Pradel et al. (2018) mapped the AM design data and knowledge for all design phases [4]. The objective of this AM-driven design framework is to categorize, analyze, and integrate the current data from the last two design phases and backpropagate to the

P. Stavropoulos

pstavr@1ms.mech.upatras.gr

1 Laboratory for Manufacturing Systems and Automation, Department of Mechanical Engineering and Aeronautics, University of Patras, 26504 Patras, Greece detailed design. The scope of this work is to reduce design iterations to a first time right approach and exploit the advantageous nature of AM design.

At the early stages of a part's design, the design engineer should account the design aspects and design considerations (see dissemination of these definitions below) of the AM processes, acting based on the proposed design framework to meet the part's specifications and achieve optimum manufacturability. Non-compliance to AM rules is causing a bottleneck to the AM process. Supplementary features are added, or others are suppressed so that the designed part can be successfully manufactured.

A mapping of the design aspects will be presented and finally, an AM-driven design framework with a computational mindset for manufacturability will be proposed. This design gap has been identified from existing literature [5].

\section{Establishing the design aspects and considerations}

Establishing the terms design aspect and design consideration is crucial to the understanding of the AM-driven design framework (Table 1). It will also contribute to the further development of the DfAM framework (Fig. 1). 
Table 1 Nomenclature

\begin{tabular}{lll}
\hline Acronym & Definition & Meaning \\
\hline AM & Additive manufacturing & Unconventional manufacturing technology \\
DfAM & Design for additive manufacturing & A generic term used to describe rules and \\
& & parameters for a part design to be produced \\
& with an AM process \\
& Design aspect & Part's feature or process's parameter \\
& Design consideration & Any resulted outcome \\
\hline
\end{tabular}

Fig. 1 Defining Aspects and Considerations for AM Design

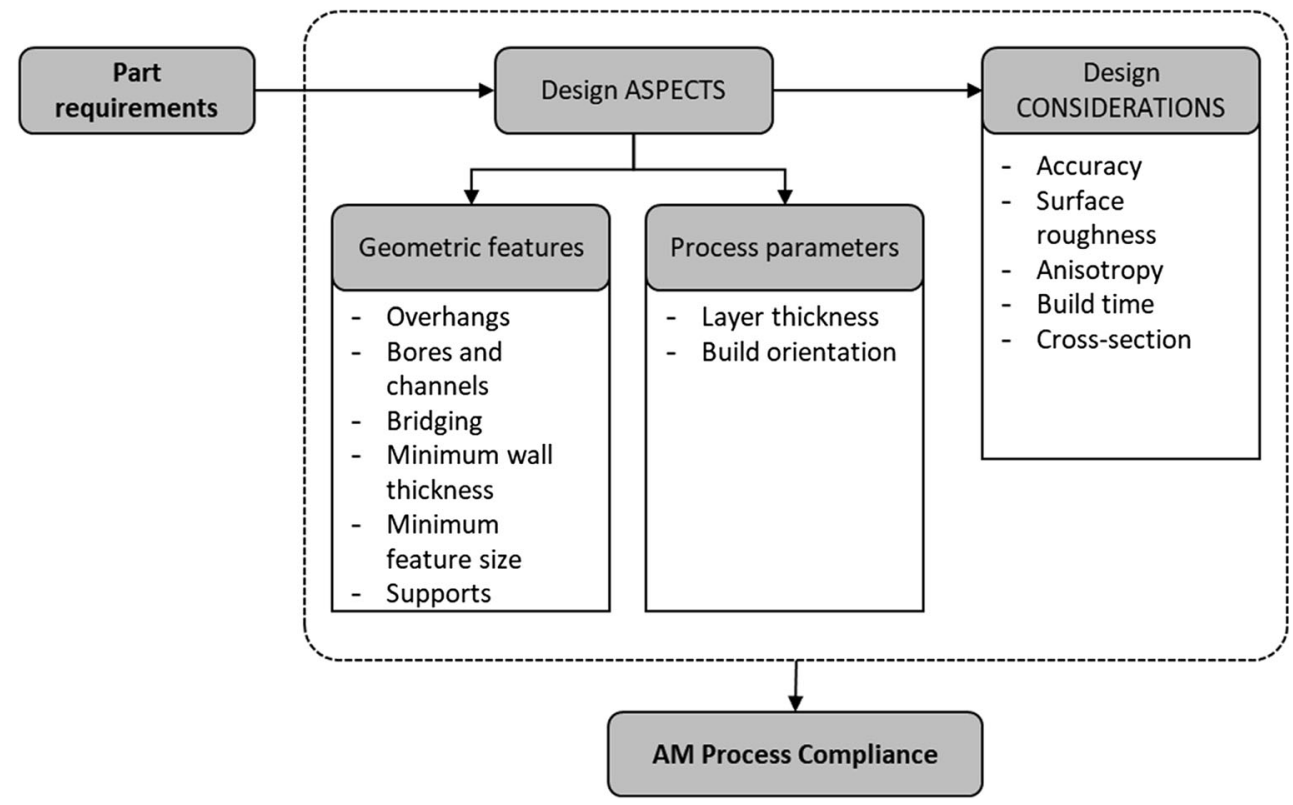

Design aspect is defined as any particular feature which can be quantified at the design phase. That includes geometric features of the part's shape (overhangs, bores, channels, etc.) and part's programming parameters (layer thickness, orientation, etc.).

Design consideration is the result on the manufactured part. These considerations can be very specific properties of the process and quantified with certain KPIs. That is, a design consideration can be a mere generic goal of the AM process
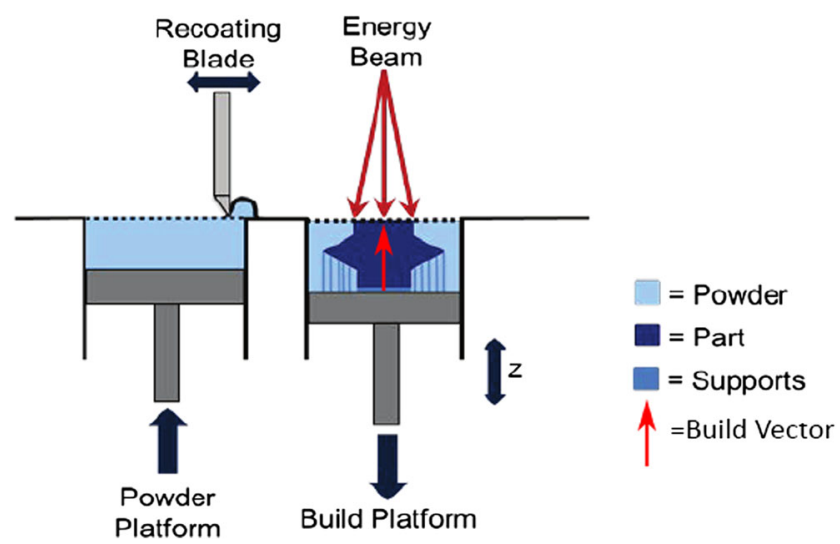

Fig. 2 Build vector depicted on a PBF AM machine (adapted from [7]) such as achieving a first time right manufactured part or a specific one like part surface roughness.

Following the establishment of these terms, comes the categorization of the current DfAM academic publications and tacit industrial knowledge in datasheets with all their parameters quantified. The next step is to develop a design framework of the bellow, dense in information blocks to extract manufacturability knowledge and thus morph the optimum part design. With conventional manufacturing processes, these aspects are mostly a concern for the production engineer rather than for the industrial designer; yet, the significance of these aspects is high for the outcome in AM technologies [4].

\subsection{Design aspects}

The design aspects of the AM process, presented below, are organized in two main categories: part's geometric features and process parameters.

\subsubsection{Geometric features}

Similar to conventional manufacturing, there are restrictions regarding the geometries that can be built. The layer-by-layer 
Solid metal below

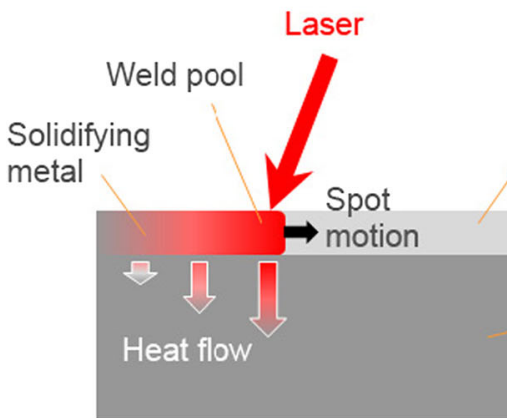

Powder below

Un-fused

powder acts

Un-fused

powder

Solid metal as an

insulator

Fig. 3 Overhanging geometries created with PBF AM technologies [8]

Fig. 4 Overhanging geometries categories

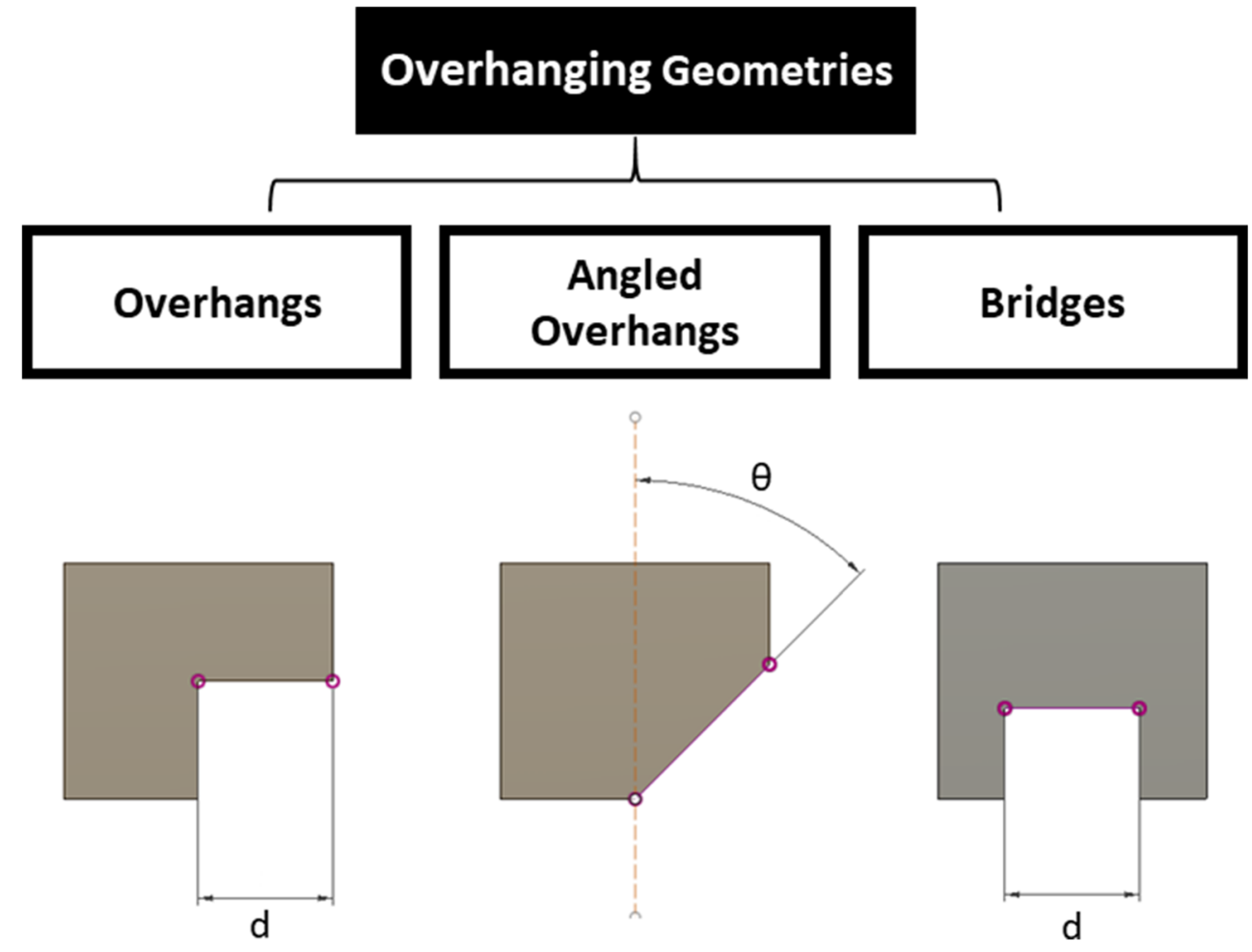

Powder below over hang is partially sintered principle followed by AM machines has its limitations since each layer must be built directly above the previous one [6]. That is, not every geometry is possible as each geometrical feature must obey to a certain geometrical continuity. Once this geometric continuity is overlooked in the design, the resulting part will suffer in its integrity (e.g., deformation, porous mass, reduced density). The design aspects that determine the quality of the outcome are presented in the following chapters.

Overhanging geometries Manufacturing overhanging geometries is a trite, yet challenging feature for the majority of the

\footnotetext{
${ }^{0}$ Manufacturability for conventional process is a duality. A feature can or cannot be manufactured. Yet for AM process, there are intermediate states where a feature can be manufactured with the aid of support structures
}

AM processes. A generic definition of an overhanging geometry is any geometry whose orientation is not parallel to the build vector (Fig. 2). The ability of the AM machine to manufacture a layer of material displaced to the previous, defines its ability to create overhanging geometries. The magnitude of this layer's parallel shift sets the limit for the maximum overhang length and the maximum slope angle.

However, overhanging geometries can be successfully manufactured, with the addition of support structures; yet, they might be proven of poor layer adhesion or postprocessing demanding (Fig. 3) [9, 10]. A support structure guarantees a successful build yet compromises the surface quality of the part, reason for being the support structures and part are overlapped [10]. It also decreases the efficiency of the AM process-build time, material, post-processing equipment, and process cost and contradicts its advantageous 
Table 2 Overhang limit per AM Technology

\begin{tabular}{|c|c|c|c|c|c|c|c|c|c|c|c|c|c|c|c|c|}
\hline & & & 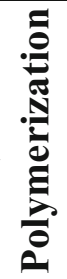 & & 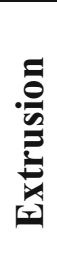 & & 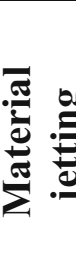 & & 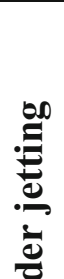 & & ? & હِ & & 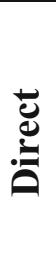 & 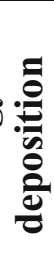 & 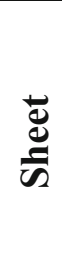 \\
\hline & ఏ્छ & $\underset{\varpi}{\leftrightarrows}$ & $\overrightarrow{\overrightarrow{0}}$ & $\overrightarrow{3}$ & 主 & $\vec{\Sigma}$ & $\overrightarrow{\mathbf{z}}$ & อิ & en & 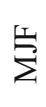 & 出 & $\sum_{\varpi}$ & $\sum_{\substack{\infty \\
\mid c}}$ & 聓 & $\sum_{\substack{ \pm \mid c}}$ & $\sum_{0}$ \\
\hline $\begin{array}{l}\text { D } \\
\text { b. } \\
\text { త్ర }\end{array}$ & $\begin{array}{c}\text { No } \\
\text { Need }\end{array}$ & & & $\mathrm{N} / \mathrm{A}$ & & [14] & [14] & [14] & & $\begin{array}{c}\mathrm{N} / \\
\mathrm{A}\end{array}$ & & & N/A & & $\begin{array}{c}\mathrm{N} / \\
\mathrm{A}\end{array}$ & [15] \\
\hline 2 & 50 & & & & [14] & & & & & & & & & & & \\
\hline & 10 & & & & [16] & & & & [14] & & [14] & & & & & \\
\hline & 7 & & & & & & & & [17] & & & & & & & \\
\hline & 5 & & & & & & & & & & & & & & & \\
\hline & 0.5 & & & & & & & & & & & $\begin{array}{l}{[18]} \\
{[14]}\end{array}$ & & & & \\
\hline & Supports & [14] & [14] & & & & & & & & & & & [15] & & \\
\hline
\end{tabular}

net-shape manufacturing nature. Therefore, in order to increase AM manufacturability, ${ }^{1}$ it is desirable that the part only has self-supported geometrical features.

The most important overhanging geometries that need to abide AM limits are presented (Fig. 4).

Overhangs Overhangs are one-sided abrupt geometry changes. The horizontal distance an AM machine can build without supports is limited and if exceeded, the whole build could fail. The limit of an overhang length is affected by numerous factors and the nature of the AM technology [11-13]. As discussed above, the AM process, the material used, and even the actual machine are variables to the equation that defines the maximum overhang length.
When part specifications call for a greater overhang, the decision to be made is whether to alter the part's geometry or maintain it and add supporting structures. Indicative overhanging lengths are presented in Table 2. The simplest way to resolve this is to replace horizontal overhangs with angled ones. In case that an angled overhang adaption is not feasible, due to the specifications and the geometry of the part, a support structure needs to be introduced to support the overhanging feature. The design decision-making process regarding horizontal overhangs is summarized in Fig. 5.

Angled overhangs Another category of the overhanging geometries is the angled overhang. In correlation with the length
Fig. 5 Overhang's decisionmaking schematic

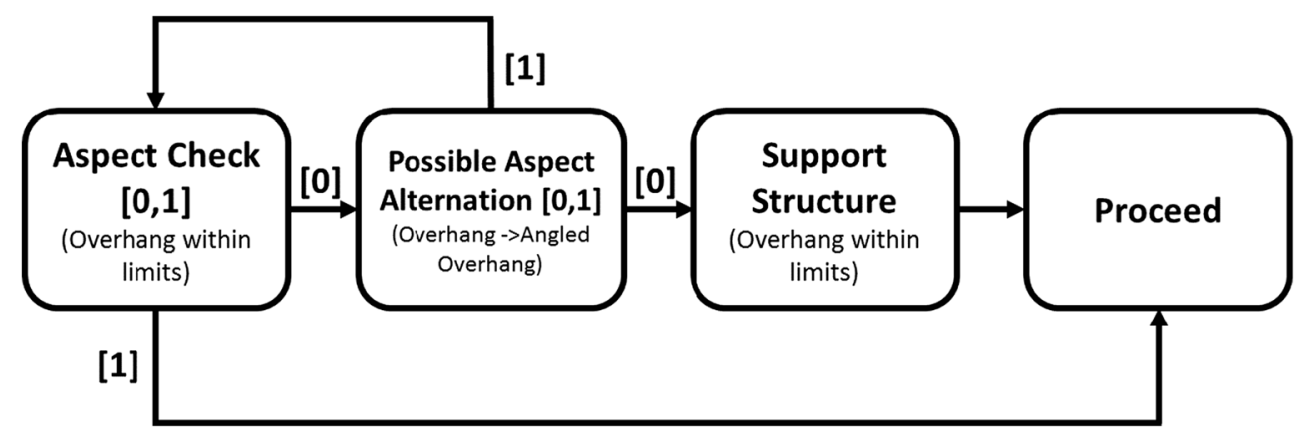


Table 3 Angled overhangs for AM technologies

\begin{tabular}{|c|c|c|c|c|c|c|c|c|c|c|c|c|c|c|c|c|}
\hline \multirow{7}{*}{ 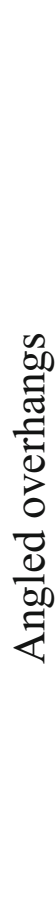 } & \multicolumn{4}{|c|}{ 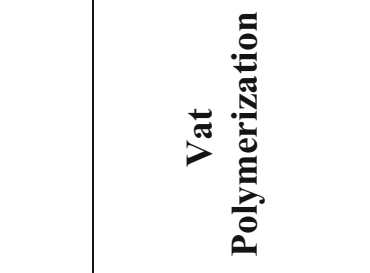 } & \multirow{2}{*}{ 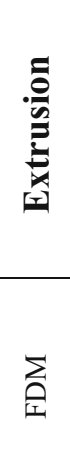 } & \multicolumn{3}{|c|}{ 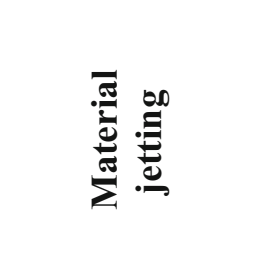 } & \multirow{2}{*}{ } & \multicolumn{4}{|c|}{ 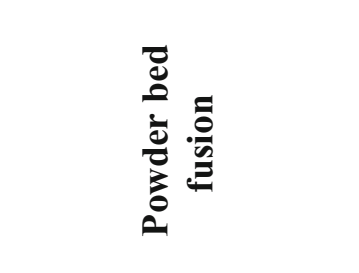 } & \multicolumn{2}{|c|}{ 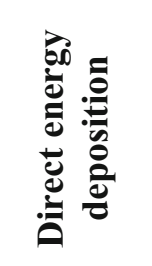 } & \multirow{2}{*}{ 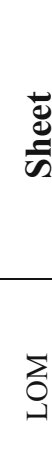 } \\
\hline & 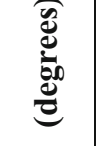 & $\underset{\leftrightarrows}{\leftrightarrows}$ & $\overrightarrow{\overrightarrow{0}}$ & 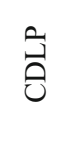 & & $\bar{\Sigma}$ & $\overrightarrow{\mathrm{Z}}$ & ิิ & & $\stackrel{I}{\Sigma}$ & $\sqrt{\tilde{n}}$ & 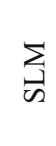 & 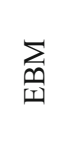 & 望 & 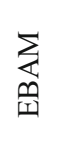 & \\
\hline & $\begin{array}{c}\text { No } \\
\text { Need }\end{array}$ & & & N/A & & [14] & [14] & [14] & [19] & N/A & & & N/A & & $\begin{array}{c}\mathrm{N} / \\
\mathrm{A}\end{array}$ & [15] \\
\hline & $60^{\circ}$ & & & & & & & & & & & {$[20]$} & & & & \\
\hline & $55^{\circ}$ & & & & & & & & & & & & & & & \\
\hline & $45^{\circ}$ & & & & [14] & & & & & & & & & & & \\
\hline & Supports & [14] & [14] & & & & & & & & & & & [15] & & \\
\hline
\end{tabular}

of the overhangs, the overhanging angle of angled overhangs is also a geometrical limiting factor to most AM technologies . Some AM technologies can produce angled overhangs of certain gradient where others cannot (Table 3). These numbers can diverge highly in certain parts whose surface quality is acceptable to be poor and if the process parameters have been set up correctly [21].

For extrusion AM technologies, extreme angled overhangs cannot be created as material cannot be deposited in midair [12]. For powder bed fusion AM technologies, the powder surrounding the part acts as a support and thus, steeper angled overhangs can be realized. That is, there is a drawback regarding surface roughness as the surrounding powder is sintered unevenly on the downward facing areas of the part.

(a)
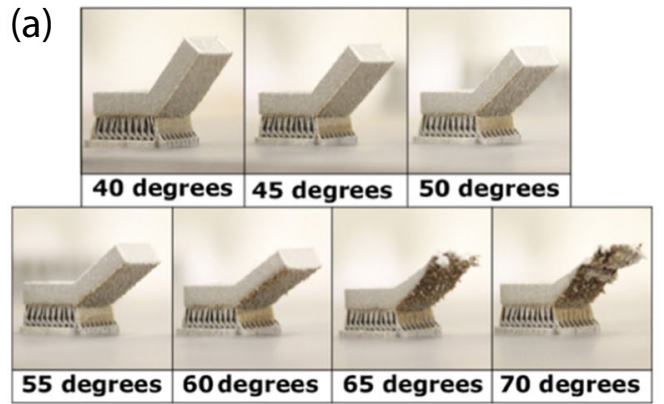

(b)

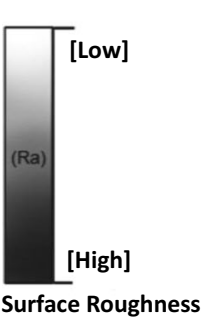

Bridging Similar to overhangs, a bridge is a horizontal geometry between two or more non-horizontal features (Fig. 6). A bridge is defined as any surface in the part geometry that is facing down between two or more features. Related to the previous restrictions, the designer must take into consideration the maximum length that the machine can bridge. If this length exceeded, the part will not be successfully manufactured (Table 4).

Bores and channels Manufacturing parts with internal geometries is a major benefit and desirable feature for AM technologies. Manufacturing internal bores that are impossible with traditional manufacturing methods is feasible with AM, without additional cost [23]. That enables profound geometrical

Fig. 6 (a) Overhanging angles in a test part manufactured with SLM technology, modified from [18]. (b) Overhanging angle-surface roughness, adapted from [22] 
Table 4 Bridging length for AM technologies

\begin{tabular}{|c|c|c|c|c|c|c|c|c|c|c|c|c|c|c|c|c|}
\hline \multirow{9}{*}{ 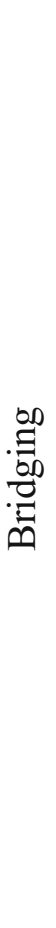 } & \multicolumn{4}{|c|}{ ث } & \multirow{2}{*}{ 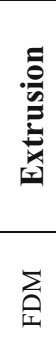 } & \multicolumn{3}{|c|}{ 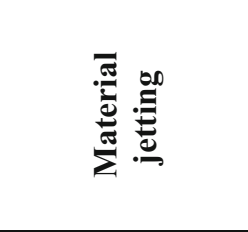 } & \multirow{2}{*}{ } & \multicolumn{4}{|c|}{ 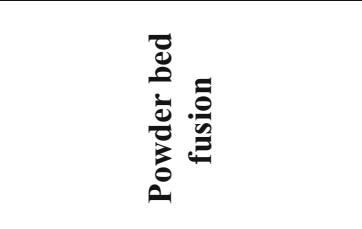 } & \multicolumn{2}{|c|}{ 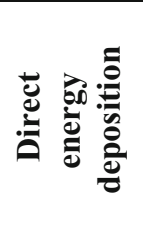 } & \multirow{2}{*}{$\frac{\underset{\mathscr{d}}{\mathscr{E}}}{\sum_{0}}$} \\
\hline & $\widehat{\widehat{\Xi}}$ & $\underset{\Xi}{\leftrightarrows}$ & $\overrightarrow{\overrightarrow{0}}$ & $\overrightarrow{\vec{\theta}}$ & & $\bar{\Sigma}$ & $\overline{\mathrm{Z}}$ & ๐ิ & & $\stackrel{\text { I }}{\Sigma}$ & $\sqrt[n]{n}$ & $\sum_{\omega}$ & $\sum_{\substack{M \\
\mid I}}$ & 兄 & 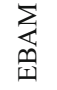 & \\
\hline & 宗 & & & N/A & & [14] & [14] & [14] & & N/A & & & N/A & $*$ & N/A & N/A \\
\hline & 2 & & & & & & & & & & & [14] & & & & \\
\hline & 10 & & & & [14] & & & & & & & & & & & \\
\hline & 20 & & & & & & & & [14] & & & & & & & \\
\hline & 50 & & & & & & & & & & [14] & & & & & \\
\hline & 80 & & & & & & & & & & & & & & & \\
\hline & 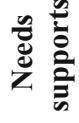 & [14] & [14] & & & & & & & & & & & & & \\
\hline
\end{tabular}

*DED technologies can bridge long distances if the head is operated with a robotic arm (counter to operation on a CNC table), as with the arms orientation freedom bridging a horizontal feature can be manufactured as a vertical one.

flexibility allowing the creation of parts with internal concave channels - achieving great heat convention capabilities or optimum fluid flow $[24,25]$ - or structural reinforcementlattice structures [26, 27]. The major AM advantage of conformal cooling channels that follow complex paths through the volume of the part increases the heat transfer capacity which in mold manufacturing processes provides efficient cooling to mold cavities and reduces cooling time [24].

To properly implement these advantageous features in the AM part design, compliance with the AM design aspects limits is mandatory. Bores and channels are subject of the overhanging geometries, acting as partially overhanging cavities (Fig. 7). That is, their limits are sometimes different as seen in Table 5.

Wall thickness There is a minimum wall thickness that is feasible to be manufactured for each AM process. This is due to the building threshold determined by the fundamental unit of the AM machine - diameter of laser beam, flow focal point, or nozzle - and the fact that the machine needs to make multiple passes to build a sufficient and solid feature. Indicative minimum wall thicknesses are shown in Table 6. Another

Fig. 7 Bores or channels are subjects overhanging geometry when perpendicularly manufactured
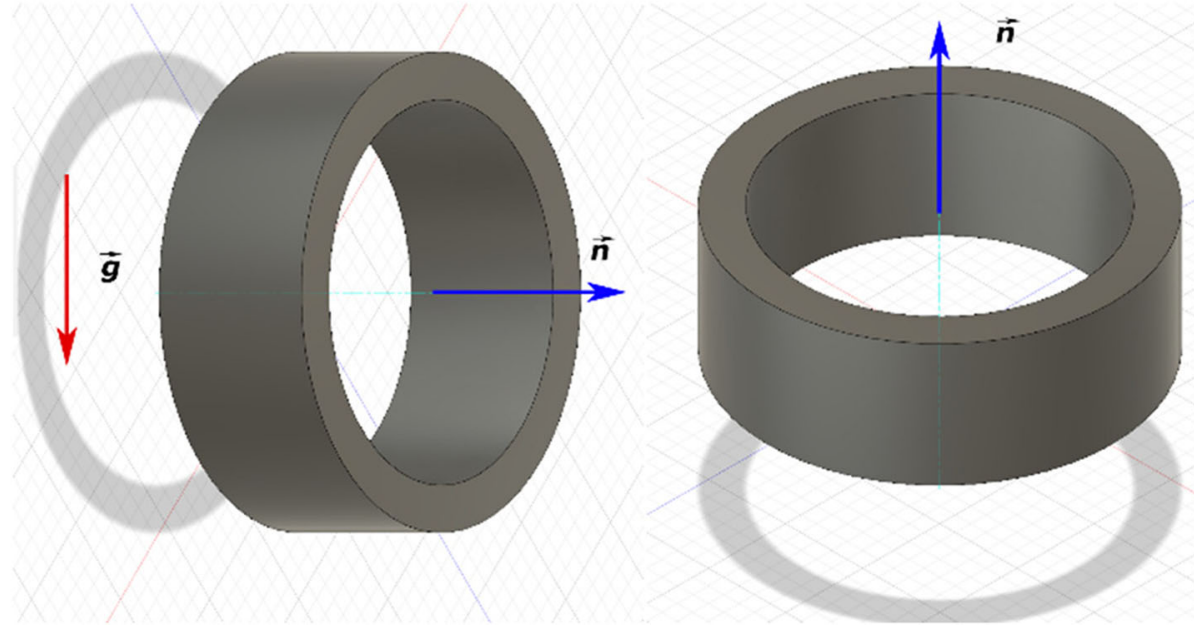
Table 5 Bores and channel's dimension limits for AM technologies

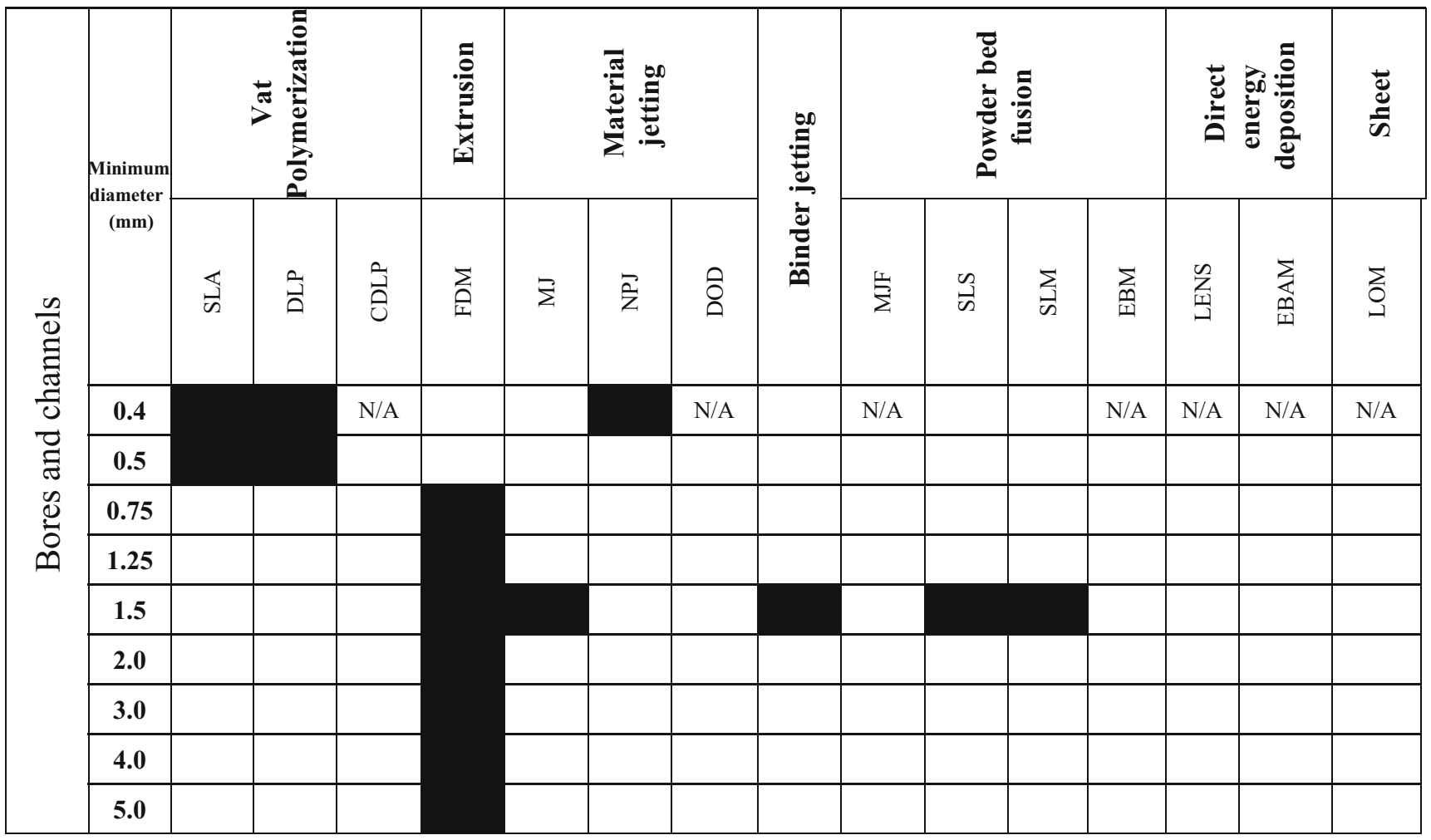

Table 6 Minimum wall thickness for AM technologies

\begin{tabular}{|c|c|c|c|c|c|c|c|c|c|c|c|c|c|c|c|c|}
\hline \multirow{13}{*}{ 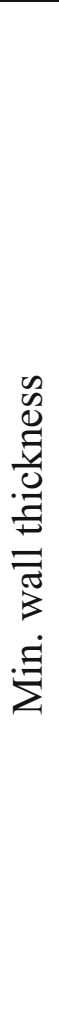 } & \multicolumn{4}{|c|}{ 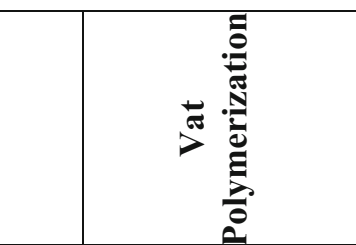 } & \multirow{2}{*}{ 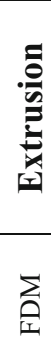 } & \multicolumn{3}{|c|}{ 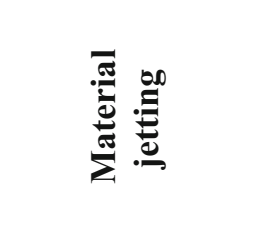 } & \multirow{2}{*}{ } & \multicolumn{4}{|c|}{ 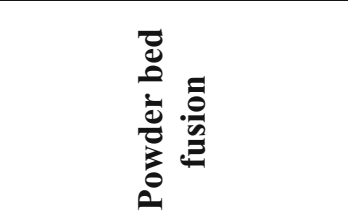 } & \multicolumn{2}{|c|}{ 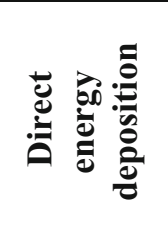 } & \multirow{2}{*}{ 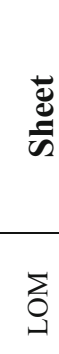 } \\
\hline & $\widehat{\mathrm{E}}$ & 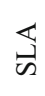 & $\overrightarrow{\vec{\theta}}$ & $\vec{\theta}$ & & $\vec{\Sigma}$ & $\overrightarrow{\mathrm{Z}}$ & Оิ & & 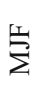 & 出 & $\sum_{i=1}$ & 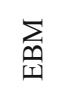 & 杢 & 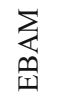 & \\
\hline & 0.1 & & & & & & N/A & N/A & & & & & N/A & N/A & N/A & N/A \\
\hline & 0.2 & & & & & & & & & & & & & & & \\
\hline & 0.25 & & & & & & & & & & & & & & & \\
\hline & 0.3 & & & & & & & & & & & & & & & \\
\hline & 0.4 & & & & & & & & & & & & & & & \\
\hline & 0.5 & & & & & & & & & & & & & & & \\
\hline & 0.6 & & & & & & & & & & & & & & & \\
\hline & 0.7 & & & & & & & & & & & & & & & \\
\hline & 1.0 & & & & & & & & & & & & & & & \\
\hline & 1.6 & & & & & & & & & & & & & & & \\
\hline & 2 & & & & & & & & & & & & & & & \\
\hline
\end{tabular}




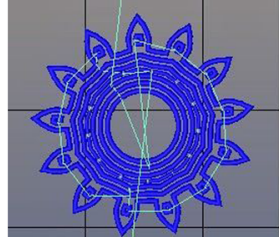

Automatic (0.58)

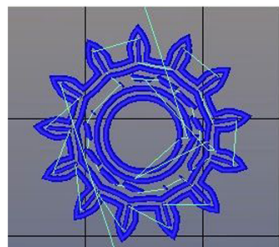

$0.80 \mathrm{~mm}$

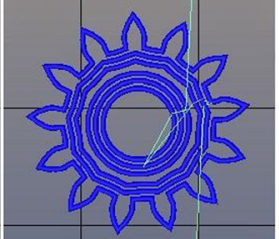

$0.60 \mathrm{~mm}$

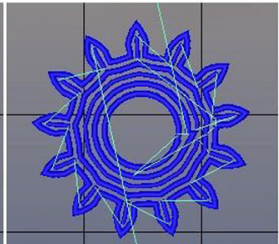

$0.82 \mathrm{~mm}$

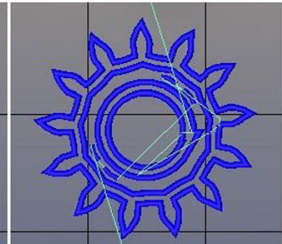

$0.88 \mathrm{~mm}$

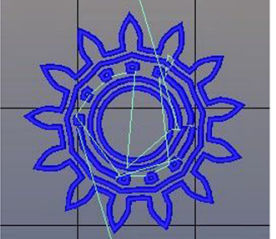

$0.70 \mathrm{~mm}$

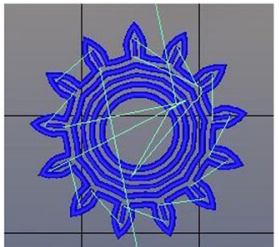

$0.84 \mathrm{~mm}$

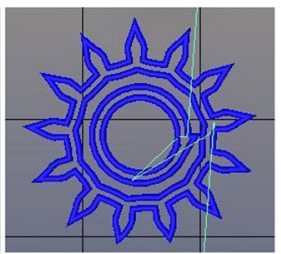

$0.90 \mathrm{~mm}$

\section{Best fit Gcode}

Fig. 8 Different path line's width for path planning for a given part's cross-section accountable parameter for thin walls is the height-to-thickness ratio. Oblong wall structures tend to collapse. ${ }^{2}$

An important path planning aspect when designing thin walls, close to the limits of the AM machine, is that some geometries cannot be precisely depicted as the slicing software which generates the G-code is not able to create the desired geometry (Fig. 8) [28, 29].

Below the lower limit of the allowed thickness, the wall feature cannot be formed, or when formed, will suffer from deformation [30]. An integer multiple of the fundamental tool path width must be used for the design. When the geometry's width that must be manufactured is not an integer multiple of the fundamental tool path width, the slicer software will have to compensate for that issue. Some of the most common ways to tackle this is to skip or overlap a certain line of the sliced surface. Another approach is to try and alter the tool path width. These solutions are, for the most part, insufficient as the integrity of the part is compromised or a generic parameter of the machine deviates from the optimum. This could cause a deviation of the dimensional accuracy and the mechanical properties.

A filling indicator is introduced to determine whether the path plan creates a sufficiently dense part.

Table 7 Smallest geometrical feature for AM technologies

\begin{tabular}{|c|c|c|c|c|c|c|c|c|c|c|c|c|c|c|c|c|}
\hline \multirow{11}{*}{ 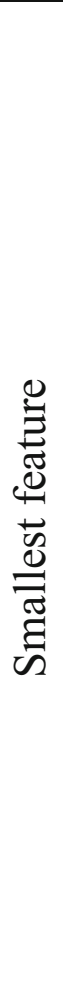 } & \multicolumn{4}{|c|}{ 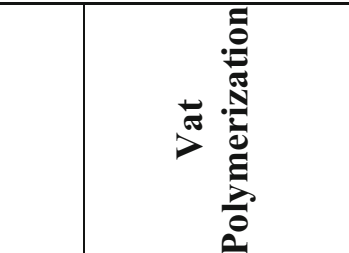 } & \multirow{2}{*}{ 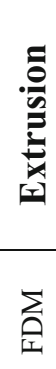 } & \multicolumn{3}{|c|}{ 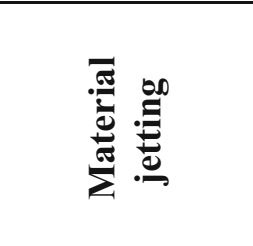 } & \multirow{2}{*}{ } & \multicolumn{4}{|c|}{ 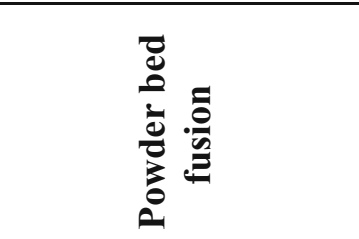 } & \multicolumn{2}{|c|}{ 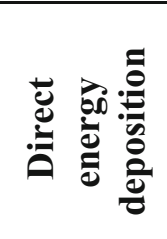 } & \multirow{2}{*}{ 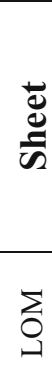 } \\
\hline & $\widehat{\mathrm{g}}$ & $\overleftrightarrow{్}$ & $\overrightarrow{\vec{a}}$ & $\overrightarrow{\vec{\theta}}$ & & $\bar{\Sigma}$ & $\overline{\mathrm{z}}$ & Оิ & & $\underset{\Sigma}{\Sigma}$ & $\stackrel{\mathscr{n}}{\tilde{\omega}}$ & $\sum_{V}$ & $\sum_{\substack{m \\
\mid I}}$ & 覮 & 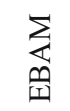 & \\
\hline & 0.1 & & & & & & & N/A & & & & N/A & N/A & N/A & N/A & \\
\hline & 0.2 & & & & & & & & & & & & & & & \\
\hline & $\begin{array}{c}0.2 \\
5\end{array}$ & & & & & & & & & & & & & & & \\
\hline & 0.3 & & & & & & & & & & & & & & & \\
\hline & 0.5 & & & & & & & & & & & & & & & \\
\hline & 0.6 & & & & & & & & & & & & & & & \\
\hline & 0.7 & & & & & & & & & & & & & & & \\
\hline & 1.6 & & & & & & & & & & & & & & & \\
\hline & 2 & & & & & & & & & & & & & & & \\
\hline
\end{tabular}


$\mathrm{FI}=\frac{D_{\mathrm{f}} \sum L_{\mathrm{i}}}{A_{\mathrm{cs}}}$

where $D_{\mathrm{f}}$ is the diameter of the fundamental build unit, $L_{\mathrm{i}}$ the length of each path, and $A_{\mathrm{cs}}$ is the surface area of the cross section.

There are physical constrains when building thin walls as they are difficult to form and can be easily distorted [31, 32]. The successful manufacturing of a thin wall is not always a hardware concern. The slicing software determines the G-code for the AM machine's fundamental building unit to follow, which can bottleneck the build [33]. A thin feature can be overlooked by the slicing software, although the machine can manufacture that feature in certain optimum scenarios [29].

Smallest features Apart from the minimum wall thickness, which is considered a 1D thin feature, there are more small features that challenge the ability of the AM machine when it comes down to manufacturability [34]. A 2D thin feature an AM machine can manufacture is usually referred to the diameter of the smallest possible pin [29]. It could also refer to the side of a rectangular or a complex-curved geometry. This aspect should be considered at the design phase, as it defines the detail that can be introduced to the part. The smallest features of AM technologies can be seen in Table 7.

\subsubsection{Process parameters}

Process parameters are selected at the slicing phase $\mathrm{e}^{3}$ of the AM process. They are highly interconnected with the AM technology and the individual machine. The proper AM design considers the build orientation and the layer thickness. In Table 8, the fundamental AM machine units that build the part layer-by-layer are presented.

Layer thickness Layer thickness is a factor that affects both the quality of the print and the build time needed to complete the part. With smaller layer thickness, a more detailed part is produced, and the staircase effect is minimized. Additionally, with smaller layer thickness, potential voids and gaps are eliminated, as the CAD file is being sliced with more precision and the geometry accuracy is maintained. On the counterpart, with thicker layers, the printing time is reduced [35]. Regarding the staircase effect, another factor that is causing it is the slope angle. As the angle increases, the cosine is proportionally increasing the stair size [36]. Indicating layer thicknesses for AM technologies are presented in Table 9. 
Table 9 Layer thickness for AM technologies

\begin{tabular}{|c|c|c|c|c|c|c|c|c|c|c|c|c|c|c|c|c|}
\hline \multirow{11}{*}{ 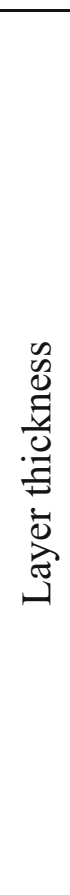 } & & \multicolumn{3}{|c|}{ 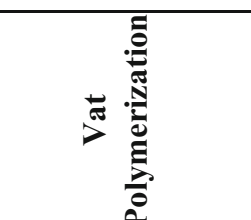 } & : & \multicolumn{3}{|c|}{ 恶 } & \multirow{2}{*}{ 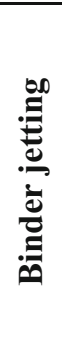 } & \multicolumn{4}{|c|}{ 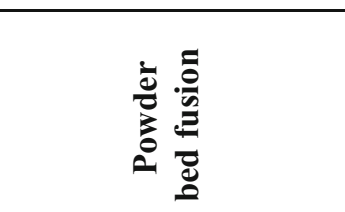 } & \multicolumn{2}{|c|}{ 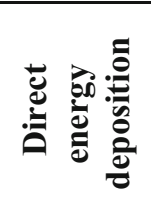 } & \multirow{2}{*}{ 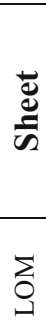 } \\
\hline & $\underset{\Xi}{\Xi}$ & $\underset{\sim}{\leftrightarrows}$ & $\overrightarrow{\vec{\theta}}$ & $\overrightarrow{\overrightarrow{0}}$ & 主 & 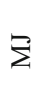 & $\overline{\mathrm{z}}$ & Оి & & 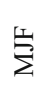 & $\stackrel{n}{n}$ & $\sum_{\sim}$ & 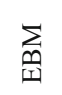 & 贡 & 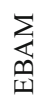 & \\
\hline & 1 & $\begin{array}{c}\text { MSLA } \\
{[37]}\end{array}$ & & & & & & & & & & & N/A & & & \\
\hline & 3 & & & & & & & & & & & & & & & \\
\hline & 6 & & & & & & & & & & & & & & & \\
\hline & 8 & & & & & & & & & & & & & & & \\
\hline & 16 & & & & & & & & & & & & & & & \\
\hline & 20 & & & & & & & & & & & [38] & & & & \\
\hline & 25 & & & & & & & & & & & & & & & \\
\hline & 32 & & & & & & & & & & & & & & & \\
\hline & 50 & & & & & & & & [14] & & & & & & & \\
\hline & 70 & & & & & & & & & & & & & & & \\
\hline & 100 & & & & & & & & & & {$[14]$} & & & & & \\
\hline & 120 & & & & & & & & & & & & & & & \\
\hline & 130 & & & & & & & & & & & & & [38] & & \\
\hline & 150 & & & & & & & & & & & & & & & \\
\hline & 380 & & & & & & & & & & & & & & & \\
\hline & 400 & & & & & & & & & & & & & & & \\
\hline & $\begin{array}{c}100 \\
0\end{array}$ & & & & & & & & & & & & & & & \\
\hline
\end{tabular}

A proposed solution to this matter is adaptive slicing. The areas where detail is needed are sliced with thin layer height, whereas areas that their quality is not affected are sliced with thicker layer height to contribute to an effective build regarding time and energy consumption [39].

Build orientation The build orientation is one of the most crucial process parameters. The orientation of the part relative to the build vector of the fundamental build unit determines which geometrical features are overhanging geometries. Subsequently, the build orientation determines the volume of support structures needed to successfully manufacture the part $[40,11]$. Moreover, it sets the axis on which the mechanical properties show anisotropic behavior.

\subsection{Design considerations}

As defined at the beginning, a design consideration is any resulted affection on the finished product. That includes mechanical properties of the part, KPIs of the AM process or even more abstract goals like first time right design and manufacture. Presented below are the most important design considerations.

\subsubsection{Anisotropic mechanical properties}

AM technologies produce parts with anisotropic mechanical properties. The anisotropic behavior is rooted to the AM nature and can be traced back to four different causes: lamellar nature, cylindrical extrusion shape (FFF technologies), short fibers within the raw material, and scaffold and lattice 
Fig. 9 a The lamellar nature. b Cylindrical extrusion shape of the FDM process. c Short fiber alignment during the extrusion process of a composite. d Lattice structures [41]
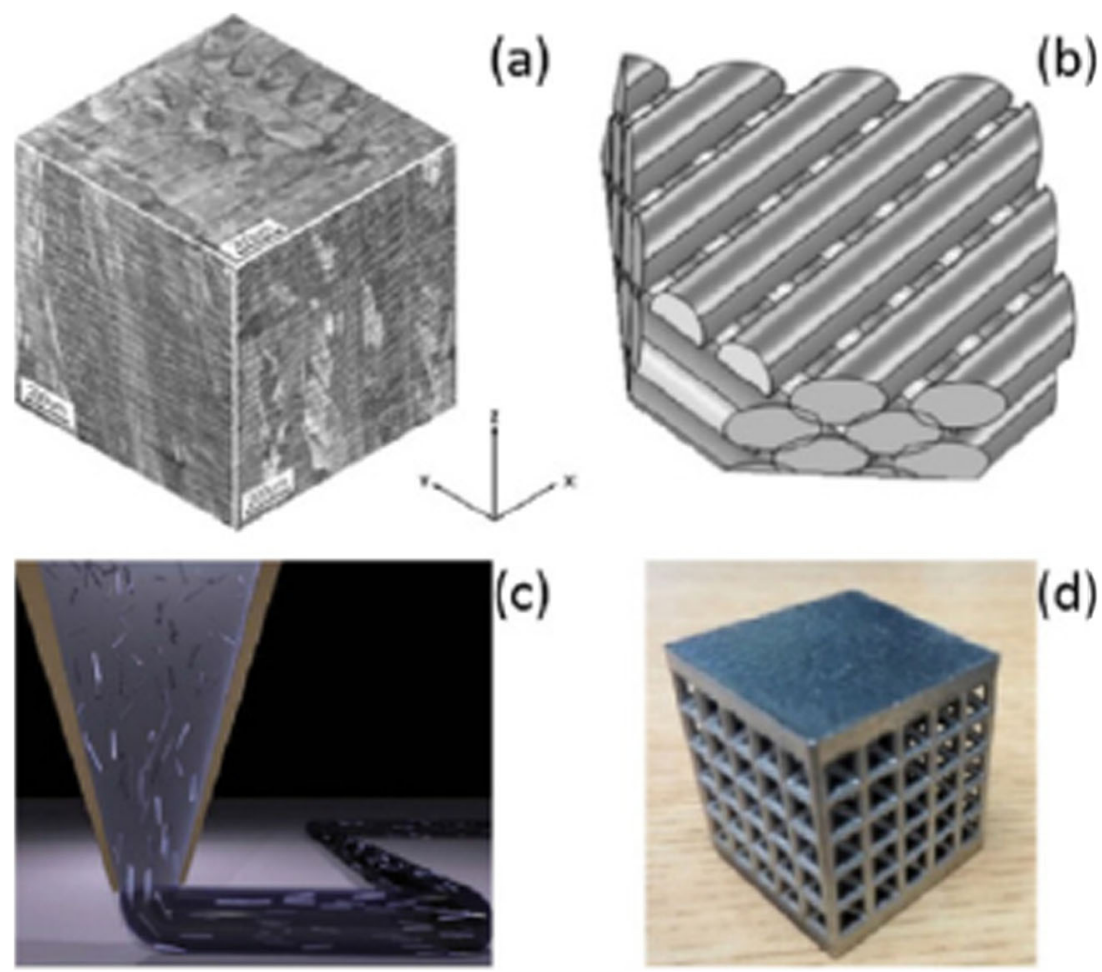

structures within the volume of the part (Fig. 9) [41, 49]. Mitigating the anisotropy with heat treatment improves to some extent the mechanical properties. However, it is not feasible for components that cannot fit to a furnace, thus it needs to be pointed as a design consideration for AM.

Having said that, there are two approaches to design a part with a given load case. The first one is to orient the designed part in such a way that the loads are received in the direction which the AM technology has the greatest mechanical strength. The other, more sophisticated approach is to shape optimize the part with the mechanical strength anisotropy in mind $[41,43]$.

\subsubsection{Accuracy (xy plane vs z axis)}

Another important design consideration is to distinguish between the machine's accuracy on the xy plane and $\mathrm{z}$ axis. The accuracy of the machine that will produce the desired part is crucial for the designer at the designing phase. For pre-assembled builds or assemblies in general, the dimensional accuracy with which the machine can manufacture has to be considered for the build to be a success.

Table 10 Surface quality for AM technologies

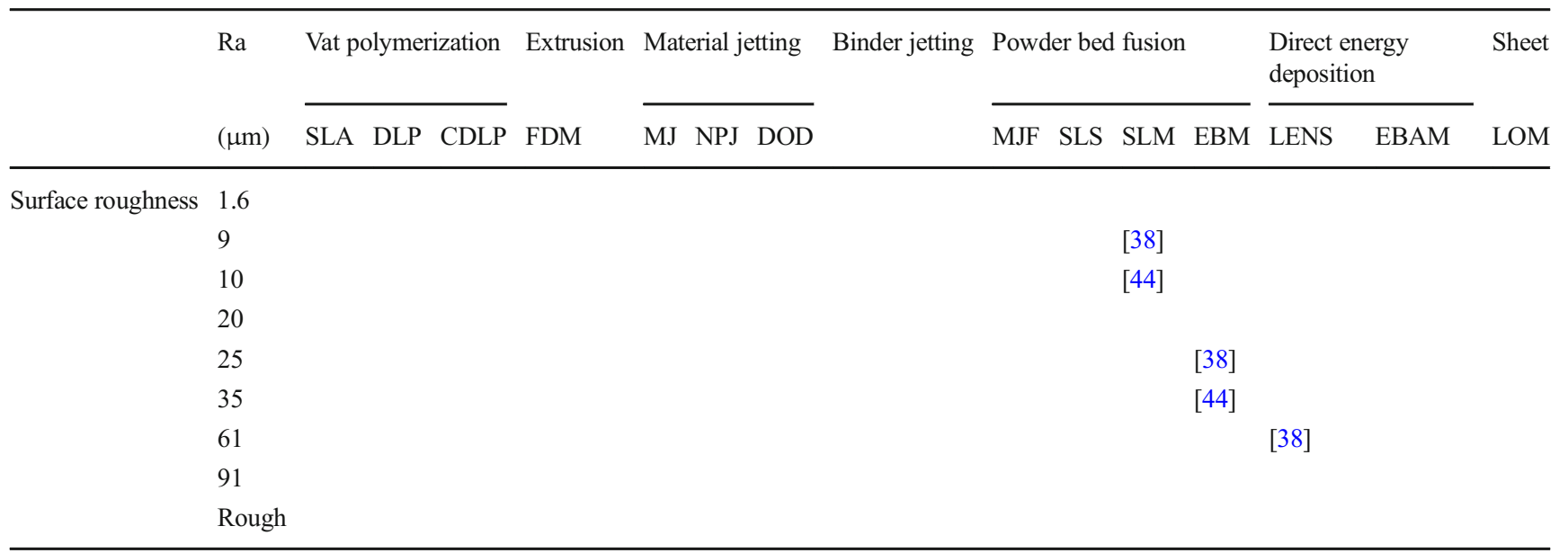




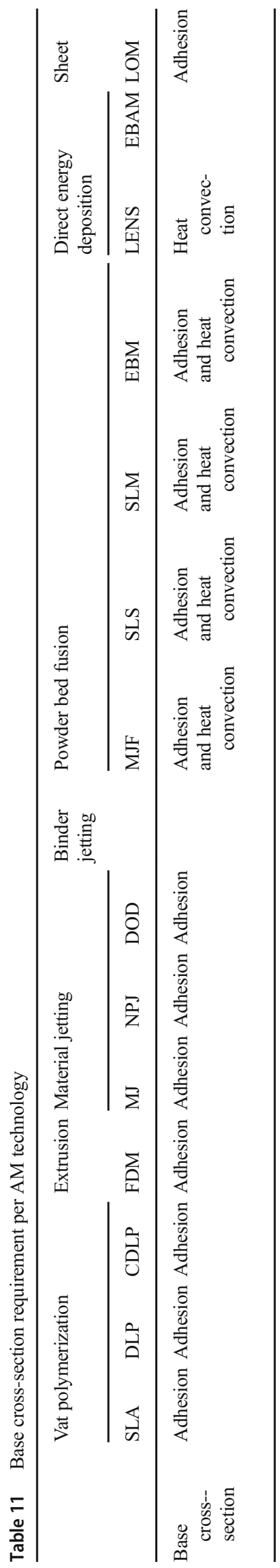

\subsubsection{Surface roughness}

The roughness of the completed part is important, as it determines the post-processing steps in order to achieve the desired surface quality. The resulted surface roughness is not uniform throughout the entire surface of the printed part. This is caused by the geometry's slope angle and the unintentional sintering under angled overhangs [19]. Another reason for surface non-uniformity is the gaps resulted from insufficient filling of the path planning (see chapter "Wall thickness"). Chryssolouris et.al. [43] have estimated the average surface roughness of SLA-produced parts as a function of the layer thickness and the angle of the inclined surface. Indicative surface roughness for AM technologies are presented in (Table 10).

\subsubsection{Build time}

The build time refers to the total time required for an AM machine to manufacture the part. The build time and build orientation of the part are highly related that is due to the fact that material deposition speeds on xy plane and $\mathrm{z}$ axis are not the same. The build unit (e.g., nozzle, laser) moves, thus builds the part, with greater speed on the xy axis, then the speed that the layers are adding up [45]. Changing the build orientation will affect the time needed for the AM machine to complete the part. Horizontally orientated parts will in general be printed faster than vertically orientated ones.

\subsubsection{Part's cross-section area}

The part's cross-section area (normal to build vector) is an important design consideration. The cross-section area affects the manufacturing process in two ways depending on the AM technology. The first one is related with the machine's build base. The second one is related with the stresses that are developed at the rest of the part's volume while its layers are manufactured. The second design consideration of the developed stresses on the part's cross-section area is related to its mechanical properties [41].

Machine's build plate and part's base consideration The first layers of the build are crucial for its completion. The part must be restrained at the build plate; thus, the adhesion between the part's base surface and the machine's plate is to be considered, apart from securing the part, through that common surface heat dissipation is achieved [46]. A thermal simulation for the heat concentration provides a picture for the design engineer, regarding residual stresses [47] The function that the part's base cross-section has per AM technology is presented in (Table 11). 
Table 12 AM technologies that require small cross section area throughout the build

\begin{tabular}{|c|c|c|c|c|c|c|c|c|c|c|c|}
\hline & Vat polymerization & \multirow[t]{2}{*}{ Extrusion } & Material jetting & \multirow[t]{2}{*}{ Binder jetting } & \multicolumn{4}{|c|}{ Powder bed fusion } & \multicolumn{2}{|c|}{$\begin{array}{l}\text { Direct energy } \\
\text { deposition }\end{array}$} & \multirow{2}{*}{$\begin{array}{l}\text { Sheet } \\
\text { LOM }\end{array}$} \\
\hline & SLA DLP CDLP & & MJ NPJ DOD & & MJF & SLS & SLM & EBM & LENS & EBAM & \\
\hline $\begin{array}{l}\text { Develops residual } \\
\text { stresses at cross-section }\end{array}$ & $\mathrm{NO}$ & Moderate & & & Yes & Yes & Significant & Yes & Yes & Yes & Yes \\
\hline
\end{tabular}

Part's cross-section and developed stresses consideration For the AM technologies that develop residual stresses (Table 12) (e.g., PBF, extrusion), it is desirable to maintain a small crosssection area to minimize residual stresses and thus deformation. This effect has a greater impact to more delicate and elongated structures such as CMF implants [48].

Lacking a coherent DfAM framework, the design process calls for numerous design iterations due to redesigning needs for adaptation to AM technologies [49]. To compensate that, a replacement of the infinite-freedom design mentality with the AM design aspects presented above, is needed. Methodically morphing the part's geometry, based on the design aspects, the design process becomes linear.

\section{Approach: mapping design steps and defining the framework}

The approach proposed in this paper uses the AM design aspects and considerations to define the part's geometry throughout the design phases. This methodology is aimed at fully utilizing the AM process's advantageous nature and anticipate the manufacturability limits of the AM technology that will manufacture the part.

This is achieved with the backpropagation of the process and manufacturing information, which morphs the shape and characteristics of the design, resulting in a part that abides the DfAM rules from the first design iteration (Fig. 10). That is, the design process is made in a more linear fashion, eliminating time-consuming design iterations.

The previous approach for the AM-driven design framework makes the design process computation orientated.

\section{Final considerations}

When designing a part to be realized with an AM process, certain design aspects and considerations need to be taken into account. The existing design for manufacturing rules (DFM) for conventional processes contribute to the designer's psychological inertia, which drives the part design away from the AM advantageous nature. The layer-wise nature of all AM

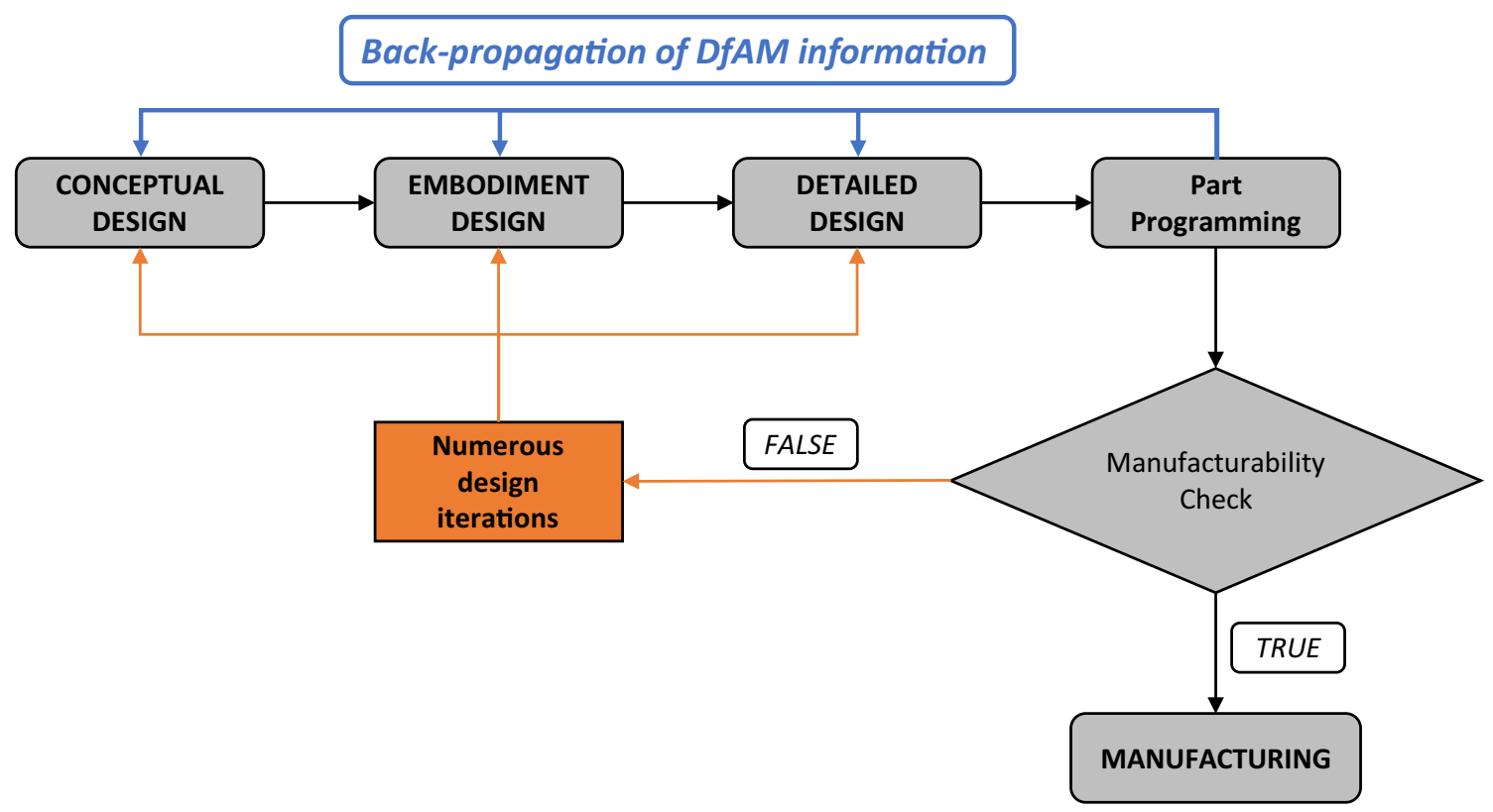

Fig. 10 Conventional (orange) and proposed (blue) design process for AM 
technologies comes along with specific geometrical limitations. Determining all design aspects that define a part's geometry and then quantifying their affection on the outcome is a necessity in order to optimize the AM process. The initial step of creating such a design framework for additive manufacturing technologies was to accurately define the design aspects, design considerations, and their dependence.

Working the part design as proposed above is of dual usefulness. First, it optimizes the conventional design process (geometry imposed by a human designer). The second contribution of this framework is related with the generative design shape optimizers. Although at their early stages, generative design seems to promise the future for part and assembly designs. The current quantification of design aspects and considerations and their true or false affection on AM manufacturability will secure the creation of optimized design that is at the same time AM ready to manufacture.

To drastically improve the AM production's efficiency, the complete design flow (conceptual, embodiment, and detail design) needs to be created with AM DfAM in mind. Only then, the AM technologies will be able to have their advantageous nature fully exploited.

\section{Further work}

This AM-driven design framework bridges the gap existing between the generic DfAM knowledge and the computational approach with the AM factors' parameterization. This unlocks the opportunity to paths where the weight of the factors and the method of the design process is implemented with data analytic methods. The AM designer's need for precognition can be replaced with intergraded ML algorithms that determine the optimum process parameters. Additionally, the morphing and manufacturability of the design can now be realized with shape algorithms. This AI approach to the AM design needs multiple data inputs from real-life manufacturing. The drift in manufacturing industry towards live process monitoring and communication between the different stages of production (IOT) serves the need for actual data to optimize the design algorithms based on the outcome result.

Funding The research leading to this paper has received funding from the European Union's Horizon 2020 research and innovation programme, under the AMable (AdditiveManufacturABLE) project, grant agreement no 768775 .

Open Access This article is distributed under the terms of the Creative Commons Attribution 4.0 International License (http:// creativecommons.org/licenses/by/4.0/), which permits unrestricted use, distribution, and reproduction in any medium, provided you give appropriate credit to the original author(s) and the source, provide a link to the Creative Commons license, and indicate if changes were made.

\section{References}

1. Bikas H, Stavropoulos P, Chryssolouris G (2015) Additive manufacturing methods and modelling approaches: a critical review. Int J Adv Manuf Technol 83(1-4):389-405. https://doi.org/ 10.1007/s00170-015-7576-2

2. Zaman UK, Rivette M, Siadat A, Mousavi SM (2018) Integrated product-process design: material and manufacturing process selection for additive manufacturing using multi-criteria decision making. Robot Comput Integr Manuf 51:169-180. https://doi.org/10. 1016/j.rcim.2017.12.005

3. Bikas H, Stavridis J, Stavropoulos P, Chryssolouris G (2016) A design framework to replace conventional manufacturing processes with additive manufacturing for structural components: a formula student case study, 49th CIRP Conference on Manufacturing Systems (CIRP-CMS 2016), vol 57, pp 710-715, 25-27 May, Stuttgart, Germany

4. Pradel P, Zhu Z, Bibb R, Moultrie J (2018) A framework for mapping design for additive manufacturing knowledge for industrial and product design. J Eng Des 29(6):291-326. https://doi.org/10. 1080/09544828.2018.1483011

5. Yang S, Zhao YF (2015) Additive manufacturing-enabled design theory and methodology: a critical review. Int J Adv Manuf Technol 80(1-4):327-342. https://doi.org/10.1007/s00170-015-6994-5

6. Spiegel G, Wright WB (2016) IV. Slicing. https://medium.com/3dprinting-in-o-p/iv-slicing-72a9515f44bc. Accessed 04/12/2018

7. Moylan S, Whitenton E, Lane B, Slotwinski J (2014) Infrared thermography for laser-based powder bed fusion additive manufacturing processes. https://doi.org/10.1063/1.4864956

8. Renishaw (2017) Design for Metal AM by Renishaw - a beginner's guide. https://www.renishaw.com/en/design-for-metal-am-abeginners-guide\%2D\%2D42652. Accessed 04/12/2018

9. Zelinski P (2018) 5 Lessons about additive manufacturing we can learn from this part. https://www.additivemanufacturing.media/ blog/post/5-lessons-about-additive-manufacturing-we-can-learnfrom-this-part-. Accessed 04/12/2018

10. Renishaw article. Additive manufacturing and the need for supports. https:/www.renishaw.com/en/can-you-build-am-partswithout-supports\%2D\%2D42173. Accessed 04/12/2018

11. Nassar AR, Reutzel EW Beyond layer-by-layer additive manufacturing - voxel-wise directed energy deposition. Applied Research Laboratory at the Pennsylvania State University, University Park

12. Jiang J, Stringer J, Xu X, Zhong RY (2018) Investigation of printable threshold overhang angle in extrusion-based additive manufacturing for reducing support waste. Int J Comput Integr Manuf 31(10):961-969. https://doi.org/10.1080/0951192x.2018. 1466398

13. Allaire G, Dapogny C, Estevez R, Faure A, Michailidis G (2017) Structural optimization under overhang constraints imposed by additive manufacturing technologies. J Comput Phys 351:295-328. https://doi.org/10.1016/j.jcp.2017.09.041

14. Redwood B, Schöffer F, Garret B (2017) The 3D printing handbook: technologies, design and applications. 3D Hubs

15. Jiang J, Xu X, Stringer J (2018) Support structures for additive manufacturing: a review. J Manuf Mater Process 2(4):64. https:// doi.org/10.3390/jmmp2040064

16. Alafaghani A, Qattawi A, Ablat MA (2017) Design consideration for additive manufacturing: fused deposition modelling. Open Journal of Applied Sciences 07:291-318. https://doi.org/10.4236/ ojapps.2017.76024

17. Yang F, Tang Y, Zhao YF (2016) Manufacturability of overhang structures fabricated by binder jetting process. Vol 2: Advanced Manufacturing. https://doi.org/10.1115/imece2016-65927 
18. Utley E (2017) An Introduction to designing for metal 3D printing. https://blogs.solidworks.com/solidworksblog/2017/06/introductiondesigning-metal-3d-printing.html. Accessed 27/11/2018

19. Thomas D (2009) The development of design rules for selective laser melting. University of Wales, Cardiff

20. Chain P Supports in 3D printing: a technology overview, 3D hubs, https://www.3dhubs.com/knowledge-base/supports-3d-printingtechnology-overview\#binder-jetting. Accessed 19/12/2018

21. Cloots M, Zumofen L, Spierings AB, Kirchheim A, Wegener K (2017) Approaches to minimize overhang angles of SLM parts. Rapid Prototyp J 23(2):362-369. https://doi.org/10.1108/RPJ-052015-0061

22. Bartolo PJS, et al (2013) High value manufacturing: advanced research in virtual and rapid prototyping. 6th International Conference on Advanced Research in Virtual and Rapid Prototyping, Leiria, Portugal, 1-5 October 2013, p 63

23. Shinde MS, Ashtankar KM (2017) Additive manufacturingassisted conformal cooling channels in mold manufacturing processes. https://doi.org/10.1177/1687814017699764.

24. Lemay M (2018) Design for additive manufacturing: (1) internal channels, https://www.linkedin.com/pulse/design-additive-manufacturing1-internal-channels-matt-lemay/. Accessed 05/12/2018

25. Pietropaoli M, Ahlfeld R, Montomoli F, Ciani A, D'Ercole M (2017) Design for additive manufacturing: internal channel optimization. J Eng Gas Turbines Power 139(10):102101. https://doi.org/ 10.1115/1.4036358

26. Beyer C, Figueroa D (2016) Design and analysis of lattice structures for additive manufacturing. J Manuf Sci Eng 138(12):121014. https://doi.org/10.1115/1.4033957

27. Valmik B, Prakash K, Vinaykumar P, Shreyans K, Kiran G, Rajkumar S (2014) A review on powder bed fusion technology of metal additive manufacturing. 4th International conference and exhibition on Additive Manufacturing Technologies-AM-2014, Septeber $1 \& 2$,2014, Banglore, India

28. Horne R (2015) Advanced perimeter tuning. https://richrap. blogspot.com/2015/01/slic3r-advanced-perimeter-tuning-3d.html. Accessed 04/12/2018

29. Yang L, Gong H, Dilip S, Stucker B (2014) An investigation of thin feature generation in direct metal laser sintering systems. Conference: 25th Annual International Solid Freeform Fabrication Symposium

30. Seepersad CC, Govett T, Kim K, Lundin M, Pinero D (2012) A designer's guide for dimensioning and tolerancing SLS parts. Annual International Solid Freeform Fabrication Symposium - An Additive Manufacturing Conference

31. Kubiak S (2017) Guidelines for wall thickness in laser sintering. https://www.additivemanufacturing.media/blog/post/guidelinesfor-wall-thickness-in-laser-sintering. Accessed 04/12/2018

32. Hoffmann P. Laboratory for advanced materials processing, https:// www.swissmem.ch/fileadmin/user_upload/Swissmem/ Veranstaltungen/2017/Zerspann/PPT_DE/15_Additive_ Manufacturing Dr. Patrik Hoffmann .pdf. Äccessed 27/11/2018

33. Papacharalampopoulos A, Stavropoulos P, Bikas H (2017) Path planning for filling 3D printed parts utilizing Hilbert curves, 15th Global Conference on Sustainable Manufacturing, (GCSM), vol 21, pp 757-764, 25-27 September, Haifa, Israel

34. Vyatskikh A, Delalande S, Kudo A, Zhang X, Portela CM, Greer JR (2018) Additive manufacturing of 3D nano-architected metals. Nat Commun 9(1). https://doi.org/10.1038/s41467-018-03071-9

35. Komineas G, Foteinopoulos P, Papacharalampopoulos A, Stavropoulos P (2018) Build time estimation models in thermal extrusion additive manufacturing processes. Procedia Manufacturing 21:647-654. https://doi.org/10.1016/j.promfg. 2018.02.167
36. Kechagias J, Zannis S, Chryssolouris G (1999) Surface roughness modelling of the Helisys laminated object manufacturing (LOM) process, 8th European Conference on Rapid Prototyping and Manufacturing, Nottingham, U.K, pp 141-152

37. Vaezi M, Seitz H, Yang S (2012) A review on 3D micro-additive manufacturing technologies. Int J Adv Manuf Technol 67(5-8): 1721-1754. https://doi.org/10.1007/s00170-012-4605-2

38. Dongdong G (2015) Laser additive manufacturing of highperformance materials, pp 15-17, https://doi.org/10.1007/978-3662-46089-4

39. Sikder S, Barari A, Kishawy HA (2014) Effect of adaptive slicing on surface integrity in additive manufacturing. Volume 1A: 34th Computers and Information in Engineering Conference. https:// doi.org/10.1115/detc2014-35559

40. Das P, Chandran R, Samant R, Anand S (2015) Optimum part build orientation in additive manufacturing for minimizing part errors and support structures. Procedia Manufacturing 1:343-354. https://doi. org/10.1016/j.promfg.2015.09.041

41. Buchanan C, Matilainen VP, Salminen A, Gardner L (2017) Structural performance of additive manufactured metallic material and cross-sections. J Constr Steel Res 136:35-48. https://doi.org/ 10.1016/j.jcsr.2017.05.002

42. Zhang P, Liu J, To AC (2017) Role of anisotropic properties on topology optimization of additive manufactured load bearing structures. Scr Mater 135:148-152. https://doi.org/10.1016/j.scriptamat. 2016.10.021

43. Chryssolouris G, Kechagias J, Moustakas P, Koutras P. (2003) An experimental investigation of the tensile strength of parts produced by laminated object manufacturing (LOM) process. CIRP Journal of Manufacturing Systems (In Proceedings of the 34th CIRP International Seminar on Manufacturing Systems, Athens, GR, 11/2001, pp 319-322). 32

44. Saunders S (2017) EBM vs DMLS 3D printing: which method and surface texture is best for titanium 3D printed implants, https:// 3dprint.com/179579/ebm-dmls-3d-printed-implants/. Accessed $19 / 12 / 2018$

45. Oswald C. Additive manufacturing design considerations for production in aerospace. http://app.emarketeer.com/resources/12517/ My_Documents/AddManufacturingDesignPart1-LAI-FINAL.pdf. Accessed 27/11/2018

46. Mukherjee T, Wei HL, De A, DebRoy T (2018) Heat and fluid flow in additive manufacturing - part II: powder bed fusion of stainless steel, and titanium, nickel and aluminum base alloys. Comput Mater Sci 150:369-380. https://doi.org/10.1016/j.commatsci. 2018.04.027

47. Mukherjee T, Zuback JS, Zhang W, DebRoy T (2018) Residual stresses and distortion in additively manufactured compositionally graded and dissimilar joints. Comput Mater Sci 143:325-337. https://doi.org/10.1016/j.commatsci.2017.11.026

48. Materialize article. AM simulation: a guide to the best part orientation and support configuration. https://www.materialise.com/en/ cases/am-simulation-best-part-orientation-support-configurationcmf-implants. Accessed 04/12/2018

49. Wright $\mathrm{S}$ (2015) 3D printing titanium: learning to learn from success. https://medium.com/3d-printing-stories/3d-printing-titaniumlearning-to-learn-from-success-9d14921c48e2. Accessed 27/11/ 2018

Publisher's note Springer Nature remains neutral with regard to jurisdictional claims in published maps and institutional affiliations. 